\title{
Socio-Economic Inequalities in Oral Health: The Case of Greece
}

\author{
John Yfantopoulos ${ }^{1}$, Constantine J. Oulis ${ }^{2}$, Platon Yfantopoulos ${ }^{3}$, William Papaioannou ${ }^{2}$ \\ ${ }^{1}$ School of Economic and Political Sciences, University of Athens, Athens, Greece \\ ${ }^{2}$ School of Dentistry, University of Athens, Athens, Greece \\ ${ }^{3}$ Department of Economics, University of York, York, UK \\ Email: "yfantopoulos@gmail.com
}

Received 10 July 2014; revised 26 August 2014; accepted 12 September 2014

Copyright (C) 2014 by authors and Scientific Research Publishing Inc.

This work is licensed under the Creative Commons Attribution International License (CC BY).

http://creativecommons.org/licenses/by/4.0/

cc) (i) Open Access

\section{Abstract}

Background: The literature on the socioeconomic determinants of oral health inequalities is rather limited. Since oral health is an integral part of general health, the investigation of oral and general health inequalities becomes an important research topic. The recent economic crisis has aggravated the level of general and oral health in Greece and evidence on inequalities is interesting for policy guidelines. Objective: The purpose of the present study is to measure the magnitude of self reported oral health inequalities in relation to certain demographic and socio-economic indicators such as gender, age, education and income status. Methods: We launched a cross-sectional survey across urban and rural population in Greece and we selected a random sample of 1500 individuals consisting of three age groups: 15 - 18 years, 35 - 45 years, and 65 to 74 years old. Selfreported general and oral health were both recorded and analyzed by means of an ordinal scale ranging from $\mathbf{0}=$ worse health to $\mathbf{1 0 0}=$ perfect health. Likert-type of scale questions were further used to capture self assessments of oral health. Dental Inequalities were assessed with reference to the following socio-economic variables: age, education, and income levels. Results: Statistically significant oral health inequalities were identified among the socio-economic groups in Greece. Lower levels of oral health were associated with those confronting financial difficulties, the aged and the less educated. The Gini Coefficient for Oral Health $G_{\text {oral }}=0.344$ (s.d. $=0.0033$ ) was higher in comparison to general health $G_{\text {general }}=0.289($ s.d. $=0.0016)$ indicating the need for public health intervention in the area of oral health. Conclusions: The paper demonstrates the significance of socioeconomic inequalities in oral health in Greece.

\section{Keywords}

Oral Health, Health Inequalities, Gini, Greece

\footnotetext{
"Corresponding author.
} 


\section{Introduction}

Over the last decades the European Commission, the WHO, the OECD and other international organizations have been expressing an increasing interest in assessing health inequalities among nations, regions and social groups. At the same time public health programmes have been launched by national Governments to tackle inequalities in health. The public health literature has indicated that there are significant inequalities in both health and oral health among the European nations which are mainly attributable to social, economic, environmental, and cultural factors. The EU common values on social justice, social inclusion and equal access to health and dental services are differently interpreted among the EU National Governments. In the OECD countries, dental care is mainly financed privately. The out of pocket payments in 2011 as proportion to total dental care expenditure ranged from $18 \%$ in the Netherlands to $97 \%$ in Spain. Tackling oral health inequalities is an important political and medical issue. At the EU level the European Commission Treaties focused on the attainment of a high level of health status among the Member States. At the Governance level the Open Method of Co-ordination was launched to facilitate the exchange of information on good practice among the Countries and improving at the same time the level of awareness for better policies towards greater efficiency and equity in the health and dental care systems.

In the area of dental care several European studies have highlighted that the lower income classes often confront financial barriers to access dental services. Due to lack or limited availability of public health services, evidence has shown that in some European Countries access to dental services is pursued by out of pocket payments. Cyprus, Bulgaria, Greece and Latvia represent the Countries at EU level where such payments constitute more than $70 \%$ of the total dental health expenditures. Further to financial barriers, geographical barriers to access have also been recorded in the literature. Living in rural or remote areas with low density of specialists and dentists and lack of specialized dental services constitute another barrier. In the literature of public health, the inequity in access has often been reported. Several studies have shown that the lower socio-economic groups are more likely to report unmet need for specialist and dental care. According to Eurobarometre surveys lower income classes find specialist and dental care "not very" or "not at all affordable". Around 82\% of the Portuguese and $75 \%$ of the Greek citizens find dental care in their countries not affordable. On the average 30\% of the Europeans think that dental care is not affordable in their countries (Eurobarometre 2007)

The purpose of this paper is to investigate the magnitude of oral health inequalities in Greece among Urban and Rural populations as well as among socioeconomic groups.

In the first section we briefly review the current literature on the determinants of oral health inequalities. In the second section we present the methodology on our sampling and the measurement of oral health variables. Section three explores the findings of the study and finally section four critically assesses the results in comparison to other studies.

\section{Literature Review}

According to White head M 1990 the term health inequalities refers to "systematic and avoidable differences in health outcomes between groups, such that poorer and/or more disadvantaged people are more likely to suffer from disease or disability and to have shorter lives than those who are more affluent”.

Oral health inequalities are affected by a variety of direct and indirect factors. On the one hand, they are associated with both the use of health services and human attitude towards oral health preservation. On the other hand, inequalities in oral health are influenced by social, economic and cultural factors as well as by the characteristics of available dental health services too.

Basic indicators are used in order to identify the people's ability of access in dental services. Such indicators are the number of visits during the last year and the use of dental services at least once during each year too. However, the results of the literature present great variation among the studies attributed to the different characteristics of the subjects under investigation. At this point, it must be mentioned that some additive factors, which influence the use of dental services, consist in its frequency, the reason why people use them and also the kind of dental care they receive. Furthermore, the factors which indicate the accessibility in dental caries have been identified through a variety of models which refer to the use of health services, such as the Andersen's, Newman's [1] and Petersen's models [2]. Except for these models, accessibility can also be observed by the measurement of socio-cultural, socio-demographic, socio-psychological and organizational factors, but also through health systems. Nevertheless, a model that includes the entity of these factors does not exist. 
According to the literature, there are some factors, which indirectly contribute in the appearance of oral diseases and problems in oral health.

Initially, the place of residence (urban-rural area) is included in these factors and according to Okullo et al. [3] it can influence the distribution of dental problems. Particularly, comparing the two areas there was noticed a higher percentage of adolescents with dental problems in urban area. Moreover, according to Oulis et al. [4] there are remarkable differences in oral health among the geographical areas, whereas this study agrees with the majority of similar ones, which indicate differences between the age groups of children and adolescents.

The appearance of oral diseases is also affected by either the personal or the family's socio-economic level, which is determined by a variety of characteristics, like the number of members, the educational level, the income and the existence of public transportation. According to Antunes et al. [5], oral health problems, which are met in cities with better socio-economic level, remain low. However, there is underlined a difference in their distribution.

In addition, bibliography has shown that people with low income not only do they affront more dental problems, but also, being compared with people in a better financial status, it is less possible that they will recover.

Another study-Burt et al. [6] concluded that both adults' and children's oral health depends on the economic and professional status, the kind of accommodation and on the psychological factor (anxiety). Finally, according to Oulis et al. parents' education level is also a significant factor influencing the appearance of oral diseases in both children and adolescents.

Furthermore, gender indirectly contributes to the inequalities in dental diseases appearance. In particular, girls seem to be more affected because of the fact that their denture grows faster and consequently there are exposed to factors which can prevent oral health problems for a further time period.

Age is also indirectly related to the inequalities in the appearance of oral health problems. Indeed, a variety of studies and researches confirm this characteristic. For example, the studies conducted by the National Center for Health Statistics [7] and the National Health and Nutrition Examination Survey [8] by the late 70's to 2000, have noticed a reduction of dental problems in adolescents compared with elderly.

Apart from these factors, poverty interacts with oral health inequalities too. It is generally noted that people with low income usually affront more dental problems. Inversely, when the economical status increases, the rate of people with oral health problems reduces.

According to Antunes et al. [5], the implementation of preventive projects reduces the appearance of dental diseases, but simultaneously it increases the unequal distribution of dental care. In this study, there was also underlined that people with lower socio-economical status take more advantage of these projects.

Finally, health systems can influence the appearance of oral diseases since there is a difference in oral health status among patients who choose either the public or the private providers of dental services. Particularly, according to Kronström et al. [9] and McGrath et al. [10] this difference is related to the type of care, whereas the study of Antunes et al. [5] expresses the same idea. Finally, both studies of Kronström et al. [9] and Tickle M. et al. [11] add that the oral health rate is strongly influenced by the type of care, which comes from the insurance or the pubic provider.

The factors related with inequalities in use of dental services can be divided into demographic and socio-economic.

On the one hand, age, gender, place of residence and education are included in demographic factors. In particular, according to some studies there are found differences in the use of dental services among age groupse.g. Osterberg et al. [12]. Moreover, according to other studies, such as the studies of Heaton et al. [13], Begewitz et al. [14] and also NCHS 1997 (USA), women use more frequently the dental services. In addition, people who live in urban areas, usually visit more frequently the dental services than these ones from rural areasManski et al. [15]. In the above study it is also noticed that the rate of dental services' use increases as the educational status increases too.

On the other hand, socio-economic factors are consisted of the availability of services and dentists, the income and the existence of insurance. These two last characteristics are determinant factors for people's capacity of responding to the cost of dental care.

More specifically, according to the study of Zavras et al. [16], Greek people with better economical status seem to use dental services compared with people with a worse one. In addition, it must be mentioned that both the existence and the type of insurance (public or private, partial or total) and services' cost too, are the basic factors, which determine people's decision on visiting the dentist. 
It is not pointless the fact that in Greece people have to dispose a higher rate of their dental expenditure because of the poor funding for dental care. It must be also underlined that in comparison with European Union state-members, Greece offers a lower percentage of public health expenditure (1.23\% versus $5 \%$ to $10 \%)$.

In conclusion, dentist's profile is an important factor, which influence dental services use. In particular, this characteristic includes: a) the accessibility to the dentist, b) manpower's comportment, c) the proper information of the patient, d) the environment and medical equipment, e) the cost and finally, f) the quality of care.

\section{Methods}

\subsection{Sample Design}

A cross-sectional household survey was conducted in Greece using the methodology of World Health Organization for oral health surveys. A representative sample of 1500 individuals was drawn using a cluster sampling process Sample selection was based on the 2001 census of the National Statistical Service of Greece stratified by age, sex, and geographical location at place of residence. Furthermore the sampling frames of our previous study on oral health survey conducted by the Dental School of the University of Athens was used to select randomly 1500 individuals who finally participated in our study. All subjects were acquainted with the purpose of the study, which was approved by the Committee for Ethics and Research of the Athens Dental School. Trained dentists were used as interviewers.

A self administered questionnaire was designed to capture:

1) the demographic aspects such as age, gender, marital status.

2) the socio-economic determinants of oral health inequalities such as education, occupation, insurance coverage, area of residence, proximity to dental services, public versus private dental services, and household income.

3) The Quality of oral health which was assessed in conjunction with quality of life using several likert scales and ordinal indicators. Validated instruments from previous studies such as the OHIP-14 were used to measure quality of life among children, adults and the elderly.

4) Finally satisfaction with public and private dental services was evaluated.

This study reports the findings from the demographic and socioeconomic determinants of oral health using a diagrammatic approach based on error bar graphs with a confidence interval of $95 \%$.

\subsection{Gini Coefficient}

Inequality is assessed using the Gini coefficient and the Lorenz curve. Gini is widely used in the literature of economics and has also been applicable in health economics and social epidemiology for examining general health as well as oral health inequalities. Its value ranges from zero to one, $0<G<1$, where $G=0$ indicates perfect equality in a full egalitarian society and $G=1$ represents a perfect unequal society. Mathematically the Gini index can be calculated as:

$$
G=\frac{\frac{1}{n^{2}} \sum_{i=1}^{n} \sum_{j=1}^{n}\left|X_{i}-X_{j}\right|}{2 \mu}
$$

where $G$ is the estimated sum of all pairwise differences between the oral health status $X_{i}$ and $X_{j}$ of two individuals. $G$ is the Gini index, $n$ is the number of observations, $X_{i}$ is the number of persons who rank their level of oral health and $\mu$ is the mean value of population's oral health

\subsection{Lorenz Curve}

The Gini Coefficient is diagrammatically described by the use of the Lorenz curve which portrays the magnitude of health inequalities. On the horizontal axis of a graphical presentation the population of a country is arranged in a hierarchical order according to level of health measured in a cardinal or ordinal scale. On the vertical axis the different levels of health are portrayed from the very lowest level of health to higher levels of health. Hence, the horizontal axis presents the cumulative proportions of population with a certain level of health and the vertical axis, the cumulative health. In an ideal, egalitarian society, the Lorenz curve coincides with the diagonal (45 degree curve) and it depicts the absolute level of perfect equality. 


\section{Results}

The total study population consisted of 798 (52.5\%) males and 712 (47.5\%) females coming from different geographic areas. In Table 1 we present the socio-demographic characteristics of our sample design. Emphasis has been given to ensure the representativeness of our subjects on the base of age, gender, education, and occupational class. In order to fulfill this objective, comparisons were established with the corresponding population indicators collected in the 2011 population census from the National Statistical Service of Greece.

\begin{tabular}{|c|c|c|}
\hline City & Number & Frequencies \\
\hline Athens & 316 & \\
\hline Thessaloniki & 300 & \\
\hline Patras & 303 & \\
\hline Ioannina & 301 & \\
\hline Kastoria & 303 & \\
\hline Urban & 1137 & \\
\hline Rural & 371 & \\
\hline \multicolumn{3}{|c|}{ Gender } \\
\hline Male & 798 & $52.5 \%$ \\
\hline Female & 721 & $47.5 \%$ \\
\hline \multicolumn{3}{|c|}{ Educational Level } \\
\hline Primary & 327 & $33.3 \%$ \\
\hline Secondary & 325 & $33.1 \%$ \\
\hline Higher & 137 & $14 \%$ \\
\hline Highest & 137 & $14 \%$ \\
\hline Master & 55 & $5.6 \%$ \\
\hline \multicolumn{3}{|c|}{ Employment Type } \\
\hline Public Sector & 157 & $17.8 \%$ \\
\hline Private Sector & 140 & $15.9 \%$ \\
\hline Self Employed & 155 & $17.6 \%$ \\
\hline Retired & 347 & $39.4 \%$ \\
\hline Household & 76 & $8.6 \%$ \\
\hline Unemployed & 5 & $0.6 \%$ \\
\hline \multicolumn{3}{|c|}{ Insurance Fund } \\
\hline IKA & 462 & $41.9 \%$ \\
\hline OGA & 140 & $12.7 \%$ \\
\hline OAEE & 206 & $18.7 \%$ \\
\hline Bank Fund & 14 & $1.3 \%$ \\
\hline DEKO & 24 & $2.2 \%$ \\
\hline Public Fund & 157 & $14.2 \%$ \\
\hline TSEMEDE & 18 & $1.6 \%$ \\
\hline TSAY & 18 & $1.6 \%$ \\
\hline Uninsured & 22 & $2 \%$ \\
\hline Other Insurance Fund & 41 & $3.7 \%$ \\
\hline
\end{tabular}


Figure 1 presents the existence of significant inequalities in subjective oral health among the young the adults and the elderly. Oral health is measured in a Visual Analogue Scale ranging from $0=$ worse possible oral health to $100=$ perfect oral health. As it is expected, oral health declines significantly with age. The average oral health in the VAS scale for the young population is around 74 and the corresponding values for the adults is 63 and for the elderly is 45 (Figure 1). This implies a significant reduction in the VAS scale by 30 points.

Educational inequalities in oral health vary significantly according to the educational status of the subject. The average VAS value for the lowest educational level (those who have completed primary education) is VAS $=48$ and for the highest educational level (holders of a post graduate degree is VAS $=68$, indicating a difference of around 20 points (Figure 2).

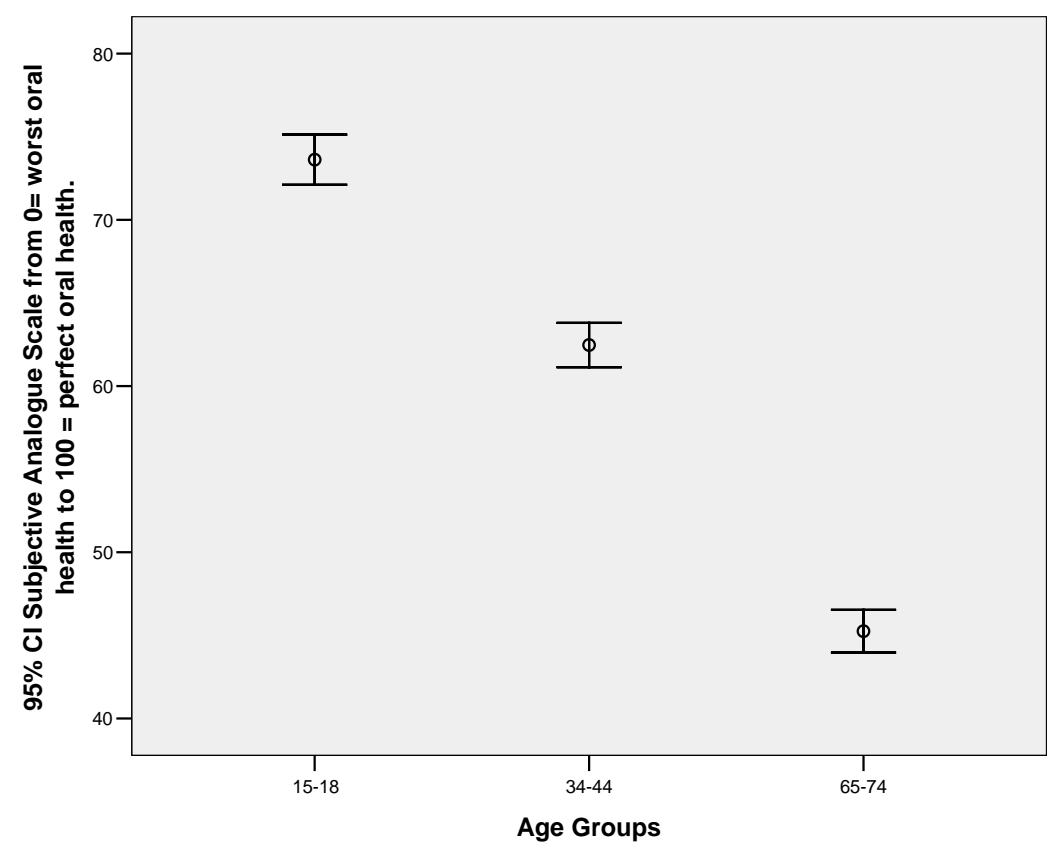

Figure 1. Oral health inequalities by age group.

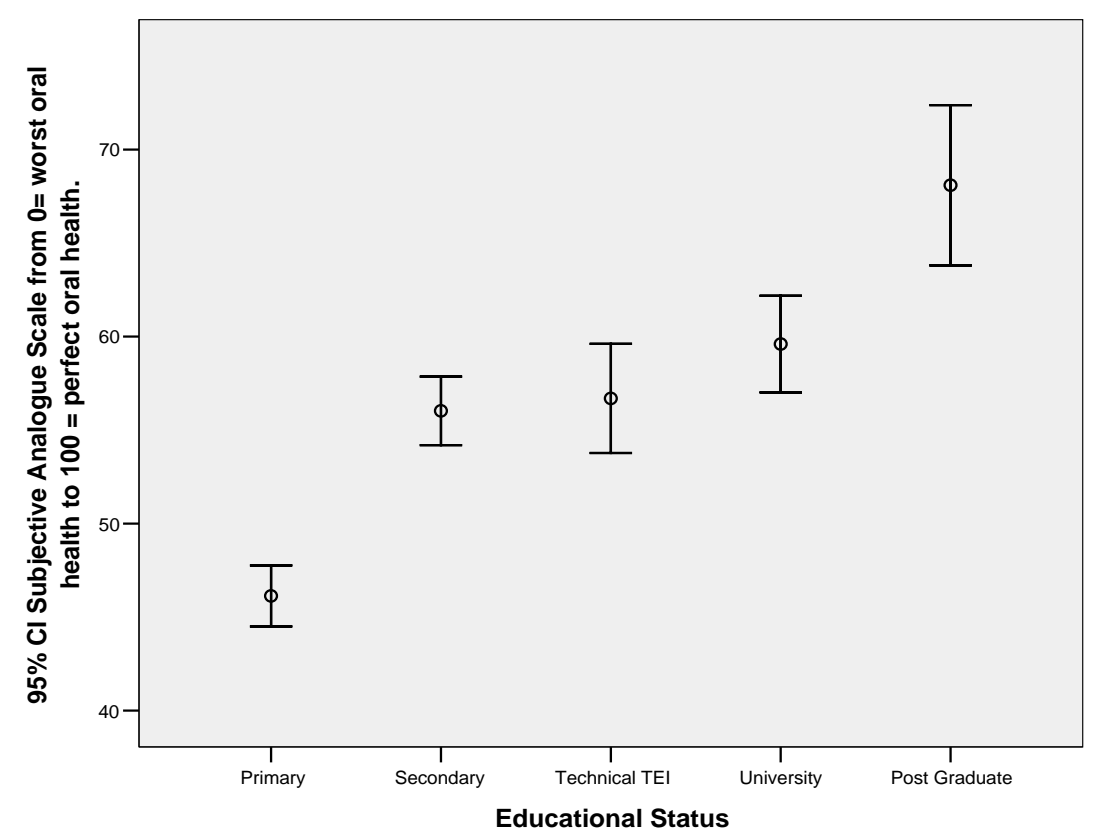

Figure 2. Oral health inequalities by educational status. 
As far as income related inequalities of oral health is concerned there is a steeper gradient among income classes varying from a VAS value of VAS $=42$ for the poor with an income less than 500 Euros per month to VAS $=96$ for the relative rich with a monthly income of more than 3000 Euros per month. Hence oral inequalities are more apparent among income classes with significant variation between as well as within various income groups (Figure 3).

Prevention, public health interventions and an overall strategy to combat oral health inequalities among the poor the less educated and the elderly would improve the overall status of oral health in Greece.

Examining the degree of oral health in relation to general health we found that the Gini coefficient for oral health was equal to $G_{\text {oral }}=0.343$ (s.d. \pm 0.0032 ) whereas the corresponding value for general health was $G_{\text {general }}$ $=0.289$ (s.d. \pm 0.0010 ).

Table 2 presents the values, the standard deviation along the lower and upper bounds of the estimated Gini coefficients. Figure 4 and Figure 5 portray the magnitude of oral and general health inequalities by the use of Lorenz curves.

\section{Discussion}

Significant socioeconomic inequalities in self rated health are reported among European countries, mostly associated with age, gender, educational level, occupation, income and social class. These studies indicate significant inequalities in mortality, morbidity and medical conditions such as chronic diseases. Health inequalities are also reported in a recent cross-national study conducted across the $27 \mathrm{EU}$ countries, where Greece presents the highest inequalities in subjective health in comparison to the rest European Union Member States.

As it was discussed in the literature review section, the number of studies dealing with the socio-economic determinants of oral health is rather limited. In Greece to the best of our knowledge there is not yet a national cross sectional study on oral health inequalities. The findings of the present study point out that significant oral

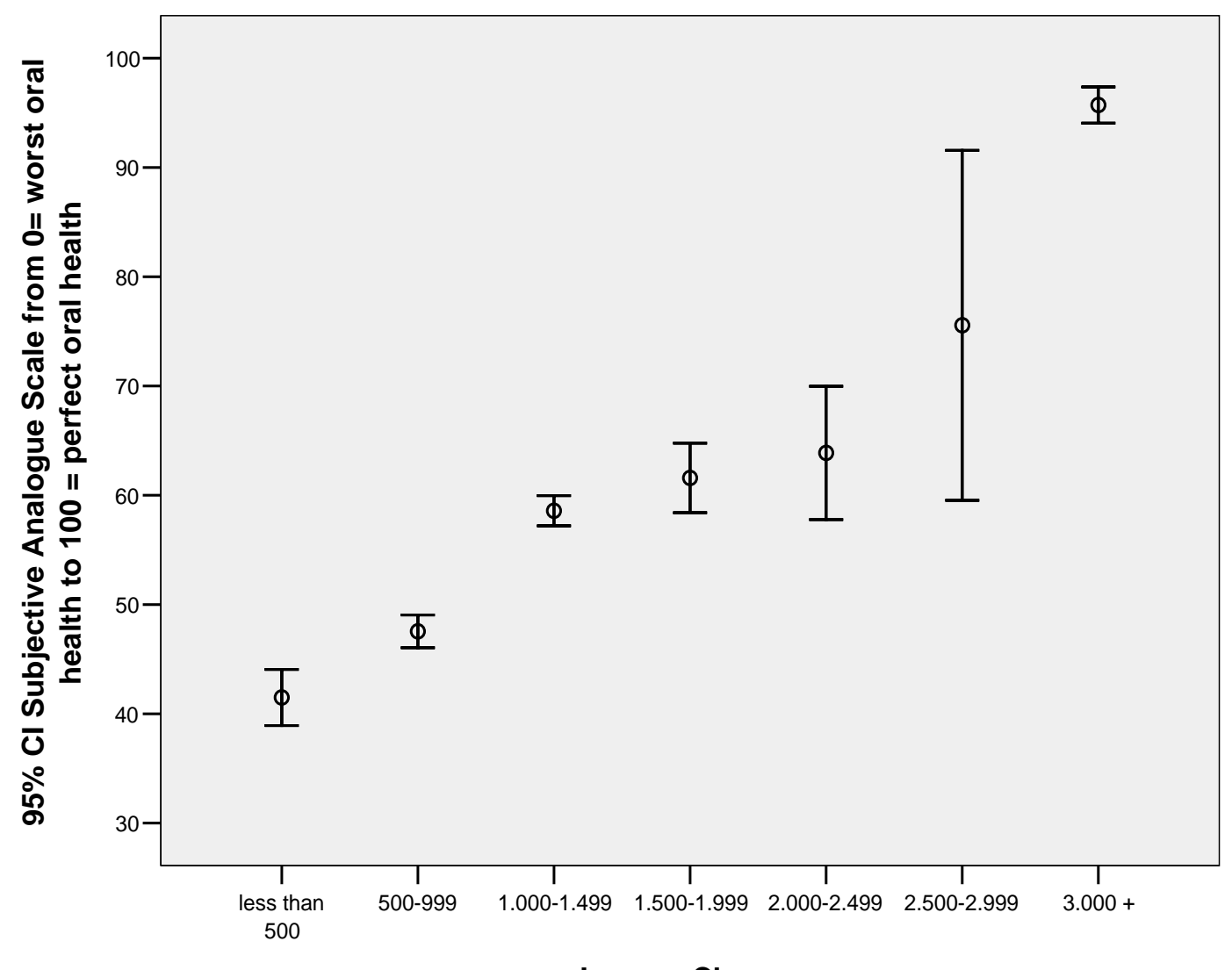

\section{Income Classes}

Figure 3. Oral health inequalities by income class. 


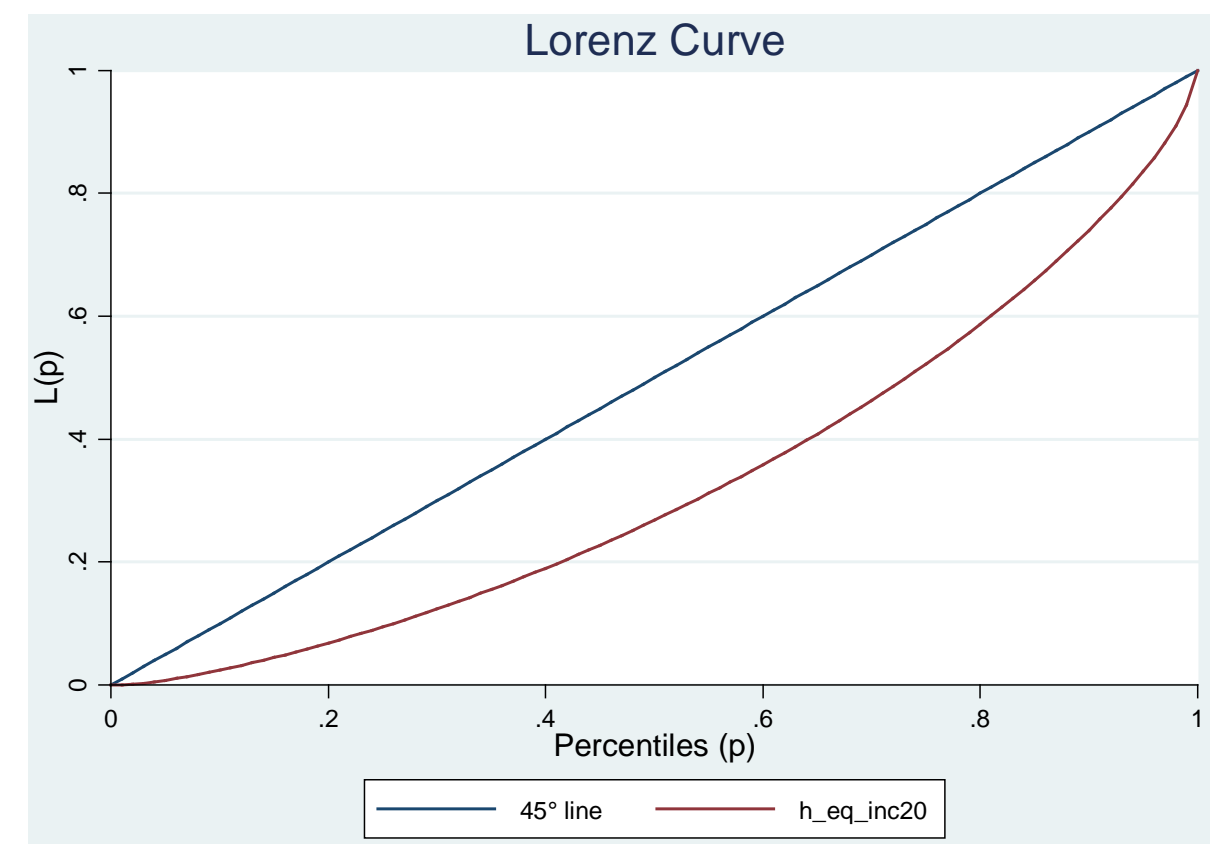

Figure 4. Gini coefficient for oral health.

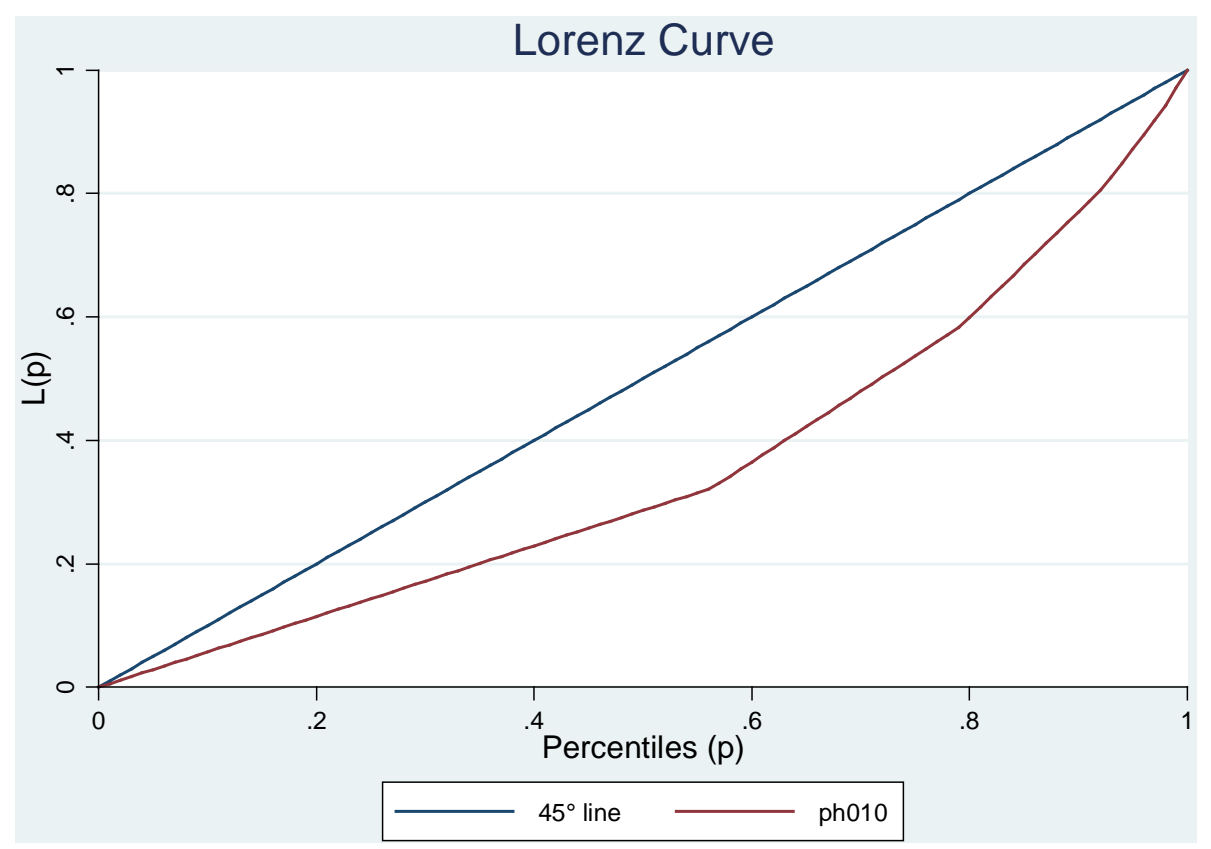

Figure 5. Gini coefficient for general health.

Table 2. Estimates of Gini coefficients for oral health and general health.

\begin{tabular}{cccccc}
\hline & Variable & Estimate & St, dev. & Lower Bound & Upper Bound \\
\hline 1: & GINI Oral Health & 0.343553 & 0.003258 & 0.337167 & 0.349940 \\
2: & GINI General Health & 0.289226 & 0.001595 & 0.286100 & 0.292351 \\
\hline
\end{tabular}

health inequalities exiting with regard to age, gender, educational and income status in Greece Similar results were reached by other oral health surveys conducted in several European Countries. 
Most of our results are consistent with those of the international literature, even though surveys are varied in the research hypothesis, the sample selection and size, as well as the methodology used. On the other hand, heterogeneous results in different countries have been produced, suggesting that differences appear to depend on cross-cultural factors and artifact explanations

Our findings should constitute a starting point for further assessments regarding the extent to which oral inequalities exist among socio-economic groups and regions in Greece. It is believed that similar national or/and international overviews and comparisons, should contribute to the decrease of oral health inequalities, the prioritization of public health policies and consequently, the fair distribution of dental and healthcare resources.

\section{Acknowledgements}

This study was part of a 3-year integrated program entitled "Assessment and Promotion of the Oral Health of the Hellenic Population" coordinated by the Hellenic Dental Association and sponsored by a Colgate Palmolive Company grant.

\section{Competing Interests}

The authors declare no competing interests in relation to this paper.

\section{References}

[1] Andersen, R. (1968) A Behavioral Model of Families Use of Health Services. Center for Health Administration Research Series, No. 25, University of Chicago, Chicago.

[2] Petersen, P.E. (2005) Sociobehavioural Risk Factors in Dental Caries-International Perspectives. Community Dentistry and Oral Epidemiology, 33, 274-279. http://dx.doi.org/10.1111/j.1600-0528.2005.00235.x

[3] Okullo, I., Åstrøm, A.N. and Haugejorden, O. (2004) Influence of Perceived Provider Performance on Satisfaction with Oral Health Care among Adolescents. Community Dentistry and Oral Epidemiology, 32, 447-455. http://dx.doi.org/10.1111/j.1600-0528.2004.00183.x

[4] Oulis, C.J., Theodorou, M., Mastrogiannakis, T., et al. (2009) Oral Health Status and Treatment Needs of the Hellenic Population. Hellenic Stomatological Review, 53, 97-120.

[5] Antunes, J.L.F., Narvai, P.C. and Nugent, Z.J. (2004) Measuring Inequalities in the Distribution of Dental Caries. Community Dentistry and Oral Epidemiology, 32, 41-48. http://dx.doi.org/10.1111/j.1600-0528.2004.00125.x

[6] Burt, B.A. (2005) Concepts of Risk in Dental Public Health. Community Dentistry and Oral Epidemiology, 33, 240247. http://dx.doi.org/10.1111/j.1600-0528.2005.00231.x

[7] National Center for Health Statistics (1996). www.cdc.gov/nchs

[8] National Health and Nutrition Examination Survey (1997, 1999). www.cdc.gov/nchs/nhanes.htm

[9] Kronström, M., Palmqvist, S., Söderfeldt, B. and Vigild, M. (2002) Utilization of Dental Health Services among MiddleAged People in Sweden and Denmark. Acta Odontologica Scandinavica, 60, 276-280. http://dx.doi.org/10.1080/00016350260248247

[10] McGrath, C. and Bedi, R. (2003) Dental Services and Perceived Oral Health: Are Patients Better off Going Private? Journal of Dentistry, 31, 217-271. http://dx.doi.org/10.1016/S0300-5712(03)00014-9

[11] Tickle, M., Milsom, K.M. and Blinkhorn, A.S. (2002) Inequalities in the Dental Treatment Provided to Children: An Example from the UK. Community Dentistry and Oral Epidemiology, 30, 335-341. http://dx.doi.org/10.1034/j.1600-0528.2002.00058.x

[12] Osterberg, T., Lundgren, M., Emilson, C.G., Sundh, V., Birkhed, D. and Steen, B. (1998) Utilization of Dental Services in Relation to Socioeconomic and Health Factors in the Middle-Aged and Elderly Swedish Population. Acta Odontologica Scandinavica, 56, 41-47. http://dx.doi.org/10.1080/000163598423054

[13] Heaton, L.J., Smith, T.A. and Raybould, T.P. (2004) Factors Influencing Use of Dental Services in Rural and Urban Communities: Considerations for Practitioners in Underserved Areas. Journal of Dental Education, 68, 1081-1089.

[14] Begewitz, I.C., Söderfeldt, B., Palmqvist, S. and Nilsen, K. (2002) Dental Care Utilization: A Study of 50- to 75-Year-Olds in Southern Sweden. Acta Odontologica Scandinavica, 60, 20-24. http://dx.doi.org/10.1080/000163502753471952

[15] Manski, R.J., Macek, M.D. and Moeller, J.F. (2002) Private Dental Coverage. Who Has It and How Does It Influence Dental Visits and Expenditures? JADA, 133, 1551-1559. http://dx.doi.org/10.14219/jada.archive.2002.0087

[16] Zavras, D., Economou, C. and Kyriopoulos, J. (2004) Factors Influencing Dental Utilization in Greece. Community Dental Health, 21, 181-188. 
Scientific Research Publishing (SCIRP) is one of the largest Open Access journal publishers. It is currently publishing more than 200 open access, online, peer-reviewed journals covering a wide range of academic disciplines. SCIRP serves the worldwide academic communities and contributes to the progress and application of science with its publication.

Other selected journals from SCIRP are listed as below. Submit your manuscript to us via either submit@scirp.org or Online Submission Portal.
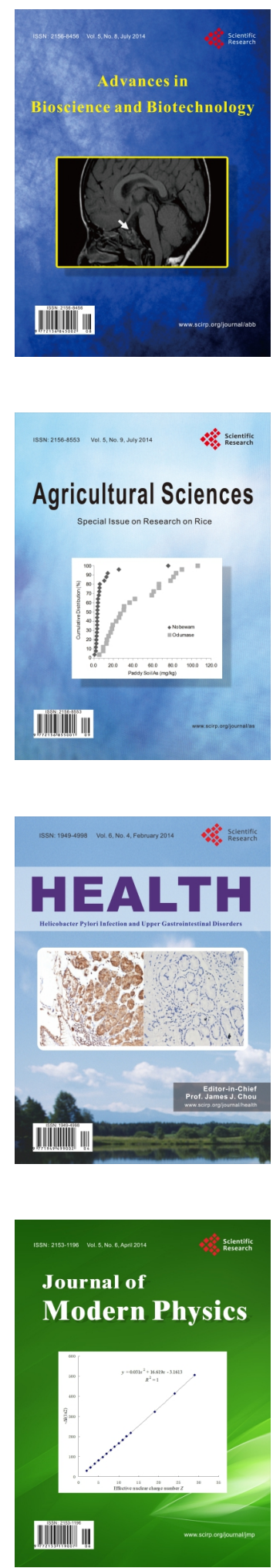
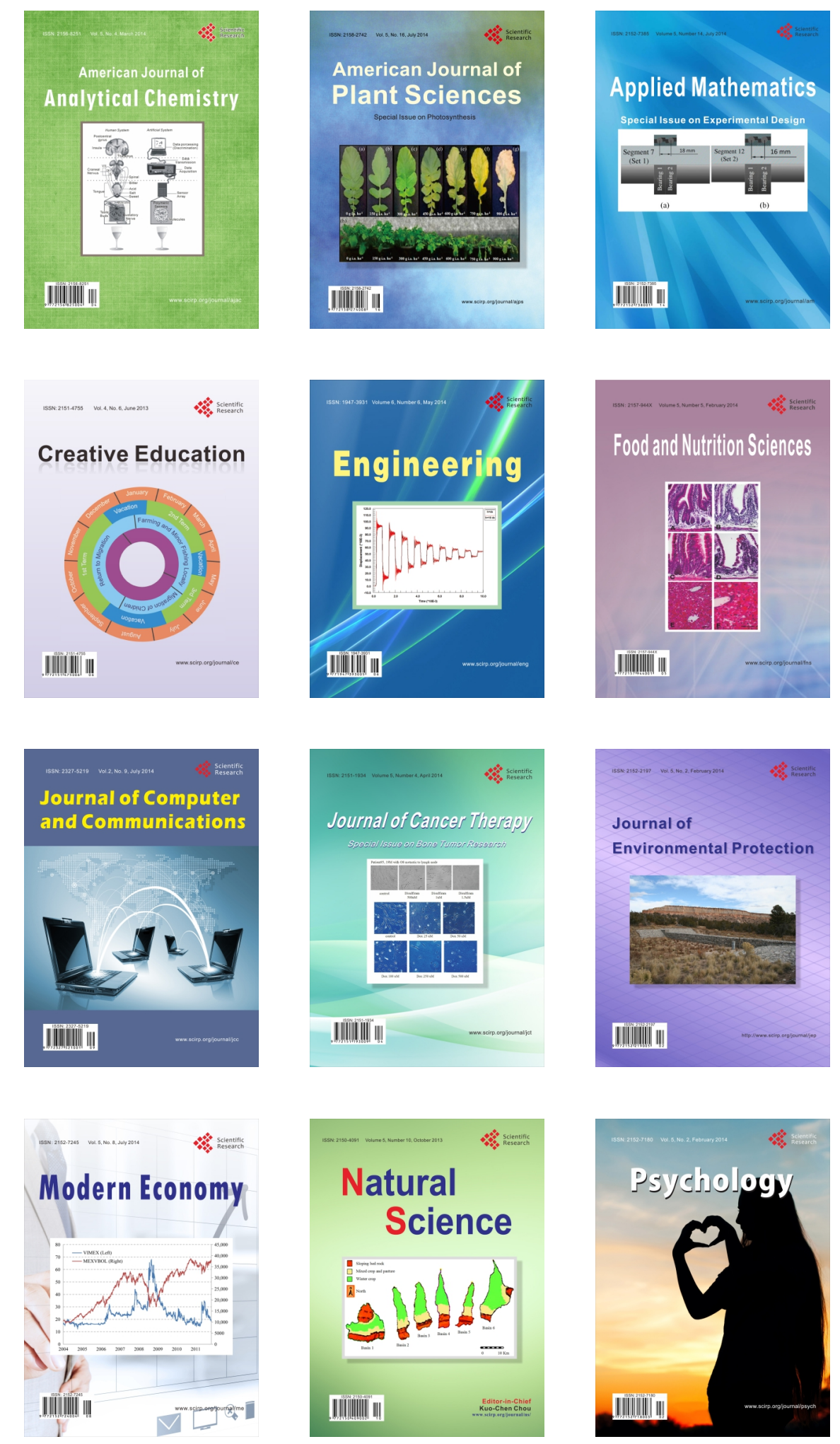